\title{
Diversity of staphylococcal cassette chromosome mec elements in nosocomial multiresistant Staphylococcus haemolyticus isolates
}

\author{
Ewa Szczuka $^{1}$ - Magdalena Krajewska ${ }^{1}$ - Dagmara Lijewska ${ }^{1}$ Karolina Bosacka $^{2}$ • \\ Adam Kaznowski ${ }^{1}$
}

Received: 5 February 2016/Revised: 6 March 2016/Accepted: 20 March 2016/Published online: 7 April 2016

(C) The Author(s) 2016. This article is published with open access at Springerlink.com

\begin{abstract}
Staphylococcus haemolyticus is the second, most frequently isolated coagulase-negative staphyloccus (CoNS) from patients with hospital-acquired infections, and it is usually resistant to methicillin and other semisynthetic penicillins. The purpose of this study was to characterize staphylococcal cassette chromosome mec ( $\mathrm{SCCmec}$ ) elements and assess the in-vitro activity of antibiotics against $60 \mathrm{~S}$. haemolyticus strains recovered from hospitalized patients. All these strains expressed methicillin resistance and carried a mecA gene. Moreover, all strains possessed a multiresistant phenotype, i.e., exhibited resistance to more than three classes of antibiotics. Eleven strains (18\%) harbored the SCCmec type V, containing $\mathrm{ccrC}$ and $m e c$ complex $C$. Three isolates harboring the $\operatorname{cr} C$ gene did not contain a known mec complex. One strain positive for mec complex $\mathrm{C}$ was not typeable for $\mathrm{ccr}$. This suggests that $c c r C$ and mec complex $C$ may exist autonomously. Only four strains carried mec complex B, whereas none of the $S$. haemolyticus harboured mec complex A. A new combination, which is mec complex B-ccrAB $B_{\text {ship, }}$, was found in $S$. haemolitycus. The $c c r A B_{\text {ship }}$ was also identified in two strains of $S$. haemolitycus in which the mec gene complex was not identified. The results of the present study indicate that in
\end{abstract}

Communicated by: Agnieszka Szalewska-Palasz

Ewa Szczuka

ewasz@amu.edu.pl

1 Department of Microbiology, Institute of Experimental Biology, Faculty of Biology, Adam Mickiewicz University, ul. Umultowska 89, Poznań 61-614, Poland

2 Department of Microbiological and Laboratory Diagnostics, Bacteriological Laboratory, Regional Hospital in Poznań, Juraszów 7/19, Poznań 60-479, Poland
S. haemolyticus the mec gene complex and the ccr genes are highly divergent. However, $c c r$ sequence analysis does not allow the identification of a new allotype, based on a cut-off value of $85 \%$ identity. The $c c r$ genes in the $S$. haemolitycus strain showed $\geq 96 \%$ sequence identity to the $c c r A B 2$ genes.

Keywords Staphylococcus haemolyticus · SCCmec · Antibiotic resistance

\section{Introduction}

Staphylococcus haemolyticus belongs to the group of coagulase-negative staphylococci (CoNS) and is a part of the normal skin flora and mucous membranes. It is an opportunistic pathogen capable of causing various types of infections, including bacteremia, meningitis, skin infection, prosthetic joint infections, and endocarditis, associated with adherence of staphylococci to medical devices and ability of these bacteria to biofilm formation (Götz et al. 2006; Kristóf et al. 2011; Nunes et al. 2005; Rodhe et al. 2006; Szczuka et al. 2015). Other virulence factors, such as exotoxins and enzymes, including nucleases, proteases, lipases, and hemolysins as well as cytotoxic activity through induction of apoptosis, also play a role in the pathogenesis of this species (Kloos and Bannerman 1999; Krzymińska et al. 2012, 2015). Among CoNS, S. haemolyticus has the highest tendency for developing resistance to multiple antibiotics, and it is usually resistant to methicillin and other semisynthetic penicillins (Barros et al. 2012; Krediet et al. 2001, 2004). The methicillin resistance of staphylococci is based on the expression of a modified penicillin-binding protein transpeptidase, with a low affinity for ß-lactams, known as PBP2a or PBP2', which 
is encoded by the mecA gene. Notably, a novel PBP2a homolog was described as being encoded by $\operatorname{mecC}$, which shares $70 \%$ identity with $m e c A$ at the DNA level. The mecC conferred cefoxitin and oxacillin resistance in S. aureus strains (Ballhausen et al. 2014). The $m e c \mathrm{~A}$ gene is carried on a mobile genetic element, called the staphylococcal chromosome mec (SCCmec) integrated into the chromosome at a specific site, located near the origin of replication. To date, eleven SCCmec types have been assigned for Staphylococcus aureus based on the composition of the ccr gene complex and the class of the mec gene complex (Ito et al. 2001, 2004; IWG-SCC 2009). The mec gene complex (A-E) is composed of a mecA gene, regulatory genes (mecRI and mecl), a hypervariable region (HVR), and an associated insertion sequence. The $c c r$ gene complex (type $c c r A, c c r B$ and $c c r C$ ) contains recombinase genes encoding recombinases responsible for the precise excision and integration of SCCmec within the bacterial chromosome. The $c c r A$ and $c c r B$ genes have been classified into different allotypes, whereas there is only one ccrC allotype (IWG-SCC 2009). Extra $c c r$ allotypes have been also identified, i.e., ccrA5 in S. pseudintermedius, ccrB6 in S. saprophyticus, ccrB7 in S. saprophyticus, ccrA5 in S. cohnii, and $c c r A B_{\text {ship }}$ in S. haemolyticus (IWG 2009; Pi et al. 2009; Zong and Lü 2010). The $c c r A B_{\text {ship }}$ products catalyse the mobility of SCCmec and might be responsible for movement of the arginine catabolic mobile element (ACME). This element carries genes encoding a arginine deiminase pathway that converts L-arginine to carbon dioxide, ATP, and ammonia. This metabolic pathway is important for bacteria survival at low $\mathrm{pH}$ and for inhibition of the immune response against bacterial infections (Pi et al. 2009). In addition to the $c c r$ and mec gene complex, the SCCmec element contains various other mobile genetic elements (MGE), e.g., plasmid, insertion sequence, and transposon mediating resistance to non- $\beta$-lactam antibiotics or heavy metals (Shore and Coleman 2013). It is believed that the increase in resistance of staphylococci to antibiotics is in part due to the presence of the SCCmec, which could be easily transferred between staphylococcal species (Hanssen and Ericson Sollid 2006). The horizontal transfer of a SCCmec type V from MRSH (methicillin-resistant $S$. haemolyticus) to methicillinsusceptible $S$. aureus strains resulted in creating MRSA clone (Berglund and Söderquist 2008).

Currently, there is great concern given to the increasing number of methicillin-resistant S. haemolyticus (MRSH) strains that are able to cause severe infections in hospitalized people. These bacteria show a remarkable tendency of developing resistance to multiple antibiotics, as well as the potential to transfer SCCmec elements. This study was undertaken to characterize the staphylococcal cassette chromosome in clinical MRSH isolates, and determine the susceptibility profiles of these isolates.

\section{Material and methods}

Bacterial strains Sixty isolates of $S$. haemolyticus were collected from clinical specimens of patients treated at the Regional Hospital in Poznań. Only isolates considered clinically relevant were included in this study. Isolates were identified by Gram staining, colony morphology, catalase reaction and by biochemical tests using the a Vitek 2 system (bioMérieux, France). The isolates were stored at in medium with $25 \%$ glycerol at $-70^{\circ} \mathrm{C}$.

Susceptibility testing Resistance to $\beta$-lactams was determined by the cefoxitin $(30 \mu \mathrm{g})$ screen test as well as by amplification of mecA gene by PCR technique. Analysis of susceptibility to the following antibiotical agents was also performed using a Vitek 2 system (bioMérieux, France) according to EUCAST recommendations (http://www.eucast.org/ clinical_breakpoints): fluoroquinolones (ciprofloxacin, levofloxacin, moxifloxacin), aminoglycosides (gentamicin and tobramycin), glycopeptides (teicoplanin and vancomycin), macrolides and lincosamides (clindamycin and erythromycin), tetracyclines (tetracycline and tigecycline), and others (linezolid, rifampin, trimethoprimsulfamethoxazole, fusidic acid and fosfomycin) .

Preparation of total DNA for PCR The total DNA was isolated and purified using the Genomic Mini DNA kit (A\&A Biotechnology, Gdynia, Poland).

SCCmec analysis The detection of mecA gene was carried out using primers and method as described previously (Zhang et al. 2005). The SCCmec analysis was carried out by identification of the mec complex and crr genes by PCR method according to the criteria set out for $S$. aureus (Zhang et al. 2005). In addition, the detection of gene lineages of mecAmecI (class A mec), mecA- IS1272 (class B mec), and mecAIS431 (class $\mathrm{C}$ mec) was performed by PCR technique using four primers assigned by Kondo et al. (2007). The presence of the novel $c c r$ allotype $\left(c c r A B_{\mathrm{SHP}}\right)$ in $S$. haemolyticus isolates was checked with primers assigned by Pi et al. (2009). The amplification products were electrophoresed in $1.5 \%$ agarose gel. The gels were stained with ethidium bromide, visualized on a UV light transilluminator, and documented with a V.99 Bio-Print system (Vilber Lourmat, Torcy, France).

\section{Sequence analysis}

The $c c r A$ and $c c r B$ genes amplicons were obtained using primers designed by Zong and Lü (2010). PCR products were purified and sequenced in a $3100 \times 1$ Genetic Analyzer (Applied Biosystems). The resulting sequences were deposited in GenBank with accession numbers KU523873 and 
KU523874. These sequences were compared with $c c r$ allotypes, available in GenBank data: ccrAl (S. aureus 45394 F, S. hominis GIFU12263), ccrA2 (S. aureus M06/0075, S. aureus JCSC6668, S. aureus N315), ccrA3 (S. aureus JKD608, S. pseudintermedius KM1381), ccrA4-2 (S. aureus CHE482), ccrA4-1 (S. aureus CHE482), ccrA5 (S. pseudintermedius KM241), ccrA $A_{\mathrm{SHP}}$ (S haemolyticus strain H9), ccrB1 (S. aureus COL), ccrB2 (S. aureus JCSC1968, $S$. epidermidis CS8), ccrB3 ( $S$. aureus TW20, S. pseudintermedius KM1381, S. cohnii WC28), ccrB4 (S aureus BK20781, S. aureus HDE288, S aureus strain CHE482), ccrB5 (S. pseudintermedius KM241), and $c c r B_{\mathrm{SHP}}($ Shaemolyticus H9). Similarity searches were carried out using BLAST programs (http://www.ncbi.nlm.nih.gov/ BLAST/).

\section{Results and discussion}

The $S$. haemolyticus strains included in this study originated from hospitalized patients with nosocomial infections. All of these isolates expressed phenotype MR and carried a mecA gene. Moreover, all isolates possessed a multiresistant phenotype, i.e., exhibited resistance to at least three of the non- $\beta$ lactam antibiotics tested. The majority of MRSH isolates were resistant to erythromycin (95\%) and gentamicin (90\%); fewer isolates were resistant to clindamycin $(77 \%)$, trimethoprimsulfamethoxazole (73\%), ciprofloxacin $(58 \%)$, tetracycline (34\%), tobramycin (27\%), and levofloxacin (18\%). Only single strains were resistant to moxifloxacin, rifampin, fusidic acid, tigecycline, and fosfomycin. Resistance among S. haemolyticus strains isolated from clinical specimens underscores the importance of this species as a reservoir for $m e c A$ genes (Nunes et al. 2005; Tabe et al. 2001). The resistance to a great range of antibiotic agents is thought to be associated with the existence of many insertion sequences, which accumulate antibiotic resistance genes, in the S. haemolyticus genome (Takeuchi et al. 2005). It should be underlined that all isolates were susceptible to vancomycin and a relatively new antibiotic - linezolid. Recently, linezolid-resistant $S$. haemolyticus has been described in European countries, the USA, China, and India (Cai et al. 2012; Gupta et al. 2012; Mazzariol et al. 2012; RodríguezAranda et al. 2009; Tewhey et al. 2014).

The SSCmec type V, containing $c c r C$ and mec complex C, was detected in 11 out of $60 \mathrm{~S}$. haemolyticus tested strains $(18 \%)$ (Table 1). The results of this study are similar to those of Ruppe et al. (2009), who demonstrated that SCCmec type V is preferentially associated with $S$. haemolyticus strains isolated from distinct geographical areas, such as Cambodia, Algeria, Mali, and Moldova. Data obtained by Bouchami et al. (2012) indicated that $c c r C$ and mec complex $C$ are most prevalent among $S$. haemolyticus. It was also found that the ccrC and mec complex $\mathrm{C}$ may exist autonomously. In our study, the $\operatorname{ccr} C$ alone was observed in three $S$. haemolyticus strains. One strain was only positive for mec complex C. Forty-nine isolates ( $82 \%$ ) were non-typeable for SCCmec using currently-available schemas based on the multiple PCR method. This can be explained by the presence of novel structures or frequent genomic rearrangements and recombination of the SCCmec element. It is noteworthy that the SCCmec types II, III and V have been detected in S. haemolyticus collected in China (Zong et al. 2011). It is believed that occurrence of different SCCmec types in China might reflect the genetic background of $S$. haemolyticus strains, connected with geographical locations. None of the studied isolates harboured the mec complex A. The four S. haemolyticus strains appeared to carry the class B mec. For two of these strains the crr gene could not be amplified. It should be noted that the class B mec complex, as well as the

Table 1 SCCmec typing results

\begin{tabular}{lllll}
\hline No. of isolates & SCCmec type & Origin & mec class & $c c r$ type \\
\hline 11 & Type V & $\begin{array}{c}\text { blood, endotracheal aspirate, } \\
\text { wound secretion, urine, } \\
\text { fluid from the peritoneal } \\
\text { cavity }\end{array}$ & class C & \\
& blood & ND & \\
3 & NT & blood & class C & ND \\
1 & NT & blood, synovial fluid & class B & $c c r A B_{\text {ship }}$ \\
2 & NT & blood, endotracheal aspirate & ND & $c c r A B_{\text {ship }}$ \\
2 & NT & blood, endotracheal aspirate & class B & ND \\
2 & NT & blood, endotracheal aspirate, & ND & ND \\
39 & NT & wound secretion, urine, & & \\
& & fluid from the peritoneal & & \\
& cavity, venous catheter & & \\
\hline
\end{tabular}

$N D$, not detected

$N T$, untypable 
ccr type 2 (SCCmec type IV), was described in a MRSH strains collected in Norway (Ibrahem et al. 2009). In summary, most $S$. haemolyticus strains did not exhibit a known mec complex. Similarly, Bouchami et al. (2012) did not detect mec gene complex in half of the MRSH isolates. In another report, in $15 \mathrm{~S}$. haemolyticus strains the mec complex was also non-typeable (Garza-González et al. 2010).

As we mentioned above, fourteen isolates carried $\operatorname{ccr} C$. Additionally, four isolates exhibited the $c c r A B_{\text {ship }}$ allotype. The results of this study are similar to reports by Pi et al. (2009), who detected $c c r A B_{\text {ship }}$ genes in eight $S$. haemolyticus strains. These $c c r A B_{\text {ship }}$-positive strains carried the class $\mathrm{C}$ mec complex. Among $S$. haemolyticus strains studied by us, two with the $c c r A B_{\text {ship }}$ allotype lacked a known mec complex, while the two remaining $c c r A B_{\text {ship }}$-positive strains carried the mec complex $\mathrm{B}$. To our knowledge, this is the first time that a unique combination of the $c c r$ gene complex and the mec gene complex (mec complex $\mathrm{B} / c c r A B_{\text {ship }}$ ) has been identified in staphylococcal strains. It should be emphasised that in 42 isolates the $c c r$ gene was not identified. We cannot exclude the loss of the $c c r$ complex from the SCCmec element. Recently, Zong (2013) found that the $m e c A$ gene may exist without $c c r$ genes, and he suggested that the $m e c A$ gene, bracketed by two copies of IS431 forming a composite transposon, could be transferred. The failure to detect $c c r$ in $S$. haemolyticus strains may be explained by the fact that they represent novel allotypes of recombinase. Therefore, newly-designed primers pairs were used to amplify $c c r A$ and $\operatorname{crr} B$ genes and the sequences of obtained amplicons were determined, deposited in GenBank with accession numbers KU523873 and KU523874, and compared to known $c c r$ sequences from GenBank database. The $c c r A$ gene (KU523874) that was identified in a $S$. haemolyticus isolate (MPU SH 68) displayed $\geq 96 \%$ sequence similarity to the $c c r A 2$ gene of the Staphylococcus aureus strains (M06/0075, JCSC6668 and N315). The $c c r B$ gene (KU523873) of MPU SH 68 shared the highest identity (97\%) with the ccrB2 gene of $S$. aureus strain JCSC1968 and S. epidermidis CS8. Thus, the nucleotide sequences of the studied $c c r A B$ genes showed that they can not be assigned to known allotypes based on the cut-off value of $85 \%$ identity. Our present data, together with previous reports, emphasize the great diversity of the SCCmec elements in S. haemolyticus (Bouchami et al. 2012; Hanssen and Ericson Sollid 2007; Pi et al. 2009; Urushibara et al. 2011; Zong and Lü 2010).

In conclusion, $S$. haemolyticus has been found to be an important source of the mec complex $\mathrm{C}$ and the $c c r C$ complex, which are components of SCCmec type V. The analysis of $c c r A$ and $c c r B$ gene sequences of the $S$. haemolitycus strain (MPU SH 68) showed their high nucleotide sequence similarity to those found in $S$. aureus and $S$. epidermidis strains. Moreover, the new combination, i.e., mec complex $\mathrm{B} / c c r A B_{\text {ship, }}$, was identified in coagulase-negative staphylococci. Our study underscores the great diversity of SCCmec structures in $S$. haemolitycus strains, as well as the importance of these bacteria as a reservoir of mecA genes.

Compliance with ethical standards This study was funded by the Faculty of Biology, Adam Mickiewicz University in Poznań. We declare that there is no conflict of interests. This article does not rely on and does not report findings from clinical studies with human participants. Human specimens collected in order to perform diagnostic tests were obtained from hospitalized patients. The bacterial strains were isolated from human specimens in hospital laboratories, which are statutorily licensed by being entered into the national registry of The National Chamber of Laboratory Diagnosticians and must comply with its code of ethics.

Open Access This article is distributed under the terms of the Creative Commons Attribution 4.0 International License (http:// creativecommons.org/licenses/by/4.0/), which permits unrestricted use, distribution, and reproduction in any medium, provided you give appropriate credit to the original author(s) and the source, provide a link to the Creative Commons license, and indicate if changes were made.

\section{References}

Ballhausen B, Kriegeskorte A, Schleimer N, Peters G, Becker K (2014) The mecA homolog mec $C$ confers resistance against $\beta$-lactams in Staphylococcus aureus irrespective of the genetic strain background. Antimicrob Agents Chemother 58:3791-3798

Barros EM, Ceotto H, Bastos MCF, dos Santos KRN, GiambiagideMarval M (2012) Staphylococcus haemolyticus as an important hospital pathogen and carrier of methicillin resistance genes. J Clin Microbiol 50:166-168

Berglund C, Söderquist B (2008) The origin of a methicillin-resistant Staphylococcus aureus isolate at a neonatal ward in Sweden - possible horizontal transfer of a staphylococcal cassette chromosome mec between methicillin-resistant Staphylococcus haemolyticus and Staphylococcus aureus. Clin Microbiol Infect 14:1048-1056

Bouchami O, Ben Hassen A, de Lencastre H, Miragaia M (2012) High prevalence of mec complex $\mathrm{C}$ and $c \mathrm{crC}$ is independent of SCCmec type V in Staphylococcus haemolyticus. Eur J Clin Microbiol Infect Dis 31:605-614

Cai JC, Hu YY, Zhang R, Zhou HW, Chen GX (2012) Linezolid-resistant clinical isolates of meticillin-resistant coagulase-negative staphylococci and Enterococcus faecium from China. J Med Microbiol 61: $1568-1573$

European Committee on Antimicrobial Susceptibility Testing (EUROCAST) (2007) Technical notes on antimicrobial susceptibility testing. http://www.eucast.org/clinical_breakpoints

Garza-González E, López D, Pezina C, Muruet W, Bocanegra-García V, Muňoz I, Ramírez C, LLaca-Díaz JM (2010) Diversity of staphylococcal cassette chromosome mec structures in coagulase-negative staphylococci and relationship to drug resistance. J Med Microbiol 59:323-329

Götz F, Bannerman T, Schleifer KH (2006) The genera Staphylococcus and Macrococcus. In: Dworkin M, Falkow S, Rosenberg E, Schleifer KH, Stackebrandt E (eds) The Prokaryotes, 3rd edn. A Handbook on the biology of bacteria: Firmicutes, Cyanobacteria vol. 4. Springer Science+Business Media, New York, pp 5-75

Gupta V, Garg S, Jain R, Garg S, Chander J (2012) Linezolid resistant Staphylococcus haemolyticus: first case report from India. Asian Pac J Trop Med 5:837-838 
Hanssen AM, Ericson Sollid JU (2006) SCCmec in staphylococci: genes on the move. FEMS Immunol Med Microbiol 46:8-20

Hanssen AM, Ericson Sollid JU (2007) Multiple staphylococcal cassette chromosomem and allelic variants of cassette chromosome recombinases in Staphylococcus aureus and coagulase-negative staphylococci from Norway. Antimicrob Agents Chemother 51: 1671-1677

Ibrahem S, Salmenlinna S, Virolainen A, Kerttula AM, Lyytikäinen O, Jägerroos H, Broas M, Vuopio-Varkila J (2009) Carriage of methicillin-resistant staphylococci and their SCCmec types in a long-term-care facility. J Clin Microbiol 47:32-37

International Working Group on the Classification of Staphylococcal CassetteChromosome Elements (2009) Classification of staphylococcal cassette chromosome mec (SCCmec): guidelines for reporting novel SCCmec elements. Antimicrob Agents Chemother 53:4961-4967

Ito T, Katayama Y, Asada K, Mori N, Tsutsumimoto K, Tiensasitorn C, Hiramatsu K (2001) Structural comparison of three types of staphylococcal cassette chromosome mec integrated in the chromosome in methicillin-resistant Staphylococcus aureus. Antimicrob Agents Chemother 45:1323-1336

Ito T, Ma XX, Takeuchi F, Okuma K, Yuzawa H, Hiramatsu K (2004) Novel type V staphylococcal cassette chromosome mec driven by a novel cassette chromosome recombinase, $\operatorname{ccr} C$. Antimicrob Agents Chemother 48:2637-2651

Kloos WE, Bannerman TL (1999) Staphylococcus and Micrococcus. In: Murray PR, Baron E, Pfallen MA, Tenover FC, Yolken R (eds) Manual of clinical microbiology. ASM Press, Washington, DC, pp 264-282

Kondo Y, Teruyo I, Ma XX, Watanabe S, Kreiswirth BN, Etienne J, Hiramatsu K (2007) Combination of multiplex PCRs for staphylococcal cassette chromosomemec type assignment: rapid identification system for mec, $c c r$, and major differences in junkyard regions. Antimicrob Agents Chemother 51:264-274

Krediet TG, Jones ME, Janssen K, Gerards LJ, Fleer A (2001) Prevalence of molecular types and mecA gene carriage of coagulase-negative staphylococci in a neonatal intensive care unit: relation to nosocomial septicemia. J Clin Microbiol 39:3376-3378

Krediet TG, Mascini EM, van Rooij E, Vlooswijk J, Pauuw A, Gerards LJ, Fleer A (2004) Molecular epidemiology of coagulase negative staphylococci causing sepsis in a neonatal intensive care unit over an 11-year period. J Clin Microbiol 42:992-995

Kristóf K, Kocsis E, Szabó D, Kardos S, Cser V, Nagy K, Hermann P, Rozgonyi F (2011) Significance of methicillin-teicoplanin resistant Staphylococcus haemolyticus in bloodstream infections in patients of the Semmelweis University Hospitals in Hungary. Eur J Clin Microbiol Infect Dis 30:691-699

Krzymińska S, Szczuka E, Kaznowski A (2012) Staphylococcus haemolyticus strains target mitochondria and induce caspasedependent apoptosis of macrophages. Antonie Van Leeuwenhoek 102:611-620

Krzymińska S, Szczuka E, Dudzińska K, Kaznowski A (2015) Virulence and the presence of aminoglycoside resistance genes of Staphylococcus haemolyticus strains isolated from clinical specimens. Antonie Van Leeuwenhoek 107:857-868

Mazzariol A, Lo Cascio G, Kocsis E, Maccacaro L, Fontana R, Cornaglia G (2012) Outbreak of linezolid-resistant Staphylococcus haemolyticus in an Italian intensive care unit. Eur J Clin Microbiol Infect Dis $31: 523-527$
Nunes APF, Teixeira LM, Bastos CCR, Silva MG, Ferreira RBR, Fonseca LS, Santos KRN (2005) Genomic characterization of oxacillin-resistant Staphylococcus epidermidis and Staphylococcus haemolyticus isolated from Brazilian medical centres. J Hosp Infect 59:19-26

Pi B, Meihong Y, Yagang C, Yunsong Y, Lanjuan L (2009) Distribution of the ACME-arcA gene among meticillin-resistant Staphylococcus haemolyticus and identification of a novel ccr allotype in ACMEacrA-positive isolates. J Med Microbiol 58:731-736

Rodhe H, Mack D, Christner M, Burdelski C, Franke G, Knobloch JK-M (2006) Pathogenesis of staphylococcal device-related infections: from basic science to new diagnostic, therapeutic and prophylactic approaches. Rev Med Microbiol 17:45-54

Rodríguez-Aranda A, Daskalaki M, Villar J, Sanz F, Otero JR, Chaves F (2009) Nosocomial spread of linezolid-resistant Staphylococcus haemolyticus infections in an intensive care unit. Diagn Microbiol Infect Dis 63:398-402

Ruppe E, Barbier F, Mesli Y, Aminata Maiga A, Radu Cojocaru R, Benkhalfat M, Benchouk S, Hassaine H, Maiga I, Diallo A, Koumare AK, Ouattara K, Soumare S, Jean-Baptiste Dufourcq JB, Nareth C, Sarthou JL, Antoine Andremont A, Ruimy R (2009) Diversity of staphylococcal cassette chromosome mec structures in methicillin-resistant Staphylococcus epidermidis and Staphylococcus haemolyticus strains among outpatients from four countries. Antimicrob Agents Chemother 53:442-449

Shore C, Coleman DC (2013) Staphylococcal cassette chromosome mec: recent advances and new insights. Int J Med Microbiol 303:350-359

Szczuka E, Grabska K, Kaznowski A (2015) In vitro activity of rifampicin combined with daptomycin or tigecycline on Staphylococcus haemolyticus biofilms. Curr Microbiol. doi:10.1007/s00284-0150821-y

Tabe Y, Nakamura A, Igari J (2001) Glycopeptide susceptibility profiles of nosocomial multiresistant Staphylococcus haemolyticus isolates. J Infect Chemother 7:142-147

Takeuchi F, Watanabe S, Baba T, Yuzawa H, Ito T, Morimoto Y et al (2005) Whole-genome sequencing of Staphylococcus haemolyticus uncovers the extreme plasticity of its genome and the evolution of human-colonizing staphylococcal species. J Bacteriol 187:72927308

Tewhey R, Gu B, Kelesidis T, Charlton C, Bobenchik A, Hindler J, Schork NJ (2014) Mechanisms of linezolid resistance among coagulase-negative staphylococci determined by whole-genome sequencing. mBio 5, 3 e00894-14

Urushibara N, Paul SK, Hossain MA, Kawaguchiya M, Kobayashi N (2011) Analysis of Staphylococcal cassette chromosome mec in Staphylococcus haemolyticus and Staphylococcus sciuri: identification of a novel $c c r$ gene complex with a newly identified $c c r A$ allotype (ccrA7). Microb Drug Resist 17:291-297

Zhang K, McClure J, Elsayed S, Louie T, Clony JM (2005) Novel PCR assay for characterization and concomitant subtyping of staphylococcal cassette chromosome mec types I to V in methicillin-resistant Staphylococcus aureus. J Clin Microbiol 43:5026-5033

Zong Z (2013) Characterization of a complex context containing mecA but lacking genes encoding cassette chromosome recombinases in Staphylococcus haemolyticus. BMC Microbiol 13:64

Zong Z, Lü X (2010) Characterization of a new SCCmec element in Staphylococcus cohnii. PLoS One 5:14016

Zong Z, Peng C, Lu X (2011) Diversity of SCCmec elements in methicillin-resistant coagulase-negative staphylococci clinical isolates. PLoS One 6, e20191 